\title{
VALORACIÓN DE LA FUNCIÓN EDUCATIVA DE LA HISTORIA
}

\author{
HISTORY EDUCATIONAL ROLE ASSESSMENT
}

Oscar Panty Neyra

\section{RESUMEN}

Ante las reiteradas interrogantes e inquietudes de ¿para qué sirve la historia? ¿cuál es su utilidad? ¿para qué aprender historia en la comunidad y en el pais?, pasamos a destacar la importancia educativa de la historia en perspectiva social, vale decir las funciones educativas que se pueden derivar del conocimiento histórico. Al respecto los historiadores han emitido juicios favorables que han puesto de relieve la utilidad social de las investigaciones históricas y su significado en el tiempo. Los siguientes enunciados sintetizan las razones de la importancia social y educativa de la historia.

Palabras clave: Historia, identidad nacional, educación ciudadana

\section{ABSTRACT}

At the repeated questions and concerns on what good is history for? What is its utility? Why learn history in the community and in the country? The educational importance of history in social perspective is highlighted; it means the educational functions that can be derived from historical knowledge. In regard to this historians have expressed favorable judgments that have highlighted the social utility of historical research and its meaning over time. The following statements summarize the reasons for the importance of social and educational history.

Keywords: History, national identity, civil education

\section{LA HISTORIA TIENE UNA IMPORTANCIA PRÁCTICA}

Tal vez ya resulta un lugar común expresar que el conocimiento del pasado nos permite comprender mejor el presente y ser más previsores con el futuro. Lo que no se puede negar es que del pasado relativamente reciente somos sus protagonistas y somos su producto inmediato. Convivimos y cargamos con el pasado. Si dirigimos nuestra mirada hacia el porvenir y queremos proyectarnos hacia él, no podemos ignorar ni prescindir de la presencia del pasado, siendo como es contradictorio, alentador y perturbador. Con mucho acierto el filósofo Benedetto Croce, idealista italiano, se expresó en La historia como hazaña de la libertad (1948) ¿Cómo emprender nueva vida, cómo crear nuestra acción sin salir del pasado, sin sobrepujarlo? No hay más que una salida, la del pensamiento que no corta relaciones con el pasado, sino que se levanta sobre él idealmente y lo trueca en conocimiento". He aquí el pasado convertido en conocimiento histórico; conocimiento que nos debe servir de herramienta para obrar más adecuadamente en el presente y enrumbar con la debida previsión social hacia el futuro. La previsión social se basa en la convicción que es posible modificar el curso de la vida futura, que el futuro se construye desde ahora, y que el futuro se construye contando con la historia.

El contemporáneo Michael Crichton en su obra Rescate en el tiempo (2000), sostiene que la historia es una herramienta intelectual que la sociedad debe utilizar para beneficio colectivo. "La finalidad de la historia es explicar el presente, decir por qué el mundo que nos rodea es como es. La historia nos cuenta por qué las cosas que valoramos son las cosas que debemos valorar. Y nos cuenta qué ha de pasarse por alto o desecharse. Eso es un verdadero poder, un poder profundo. El poder de definir a toda una sociedad. El futuro depende del pasado."

La importancia práctica de la historia radica en que auscultando el pasado podemos comprender bajo que condicionamientos hemos llegado a ser lo que

${ }^{1}$ Dr. en Ciencias Sociales. Profesor de Educación, Filosofía y Ciencias Sociales. Facultad de Educación, Comunicacióny Humanidades. Universidad Nacional Jorge BasadreGrohmann.Correoelectrónico:opanty@hotmail.com 
somos actualmente; más aún, las lecciones que podamos extraer del pasado deben servirnos para uuestra mejora continua a futuro.

\section{LA HISTORIA CONTRIBUYE AL FORTALECIMIENTO DE LA IDENTIDAD NACIONAL}

Al respecto Cristián García Godoy, miembro de la Academia Nacional de la Historia (Buenos Aires, Argentina), frente al avance de la globalización, que pone en riesgo las identidades nacionales, plantea en su ensayo Globalización, identidad nacional e idioma (2006): "Conocer, lo mejor posible, nuestra historia nacional, regional, provincial y local, a fin de saber quiénes somos, de dónde venimos y cuál es nuestro destino en cuanto comunidad diferente.", se entiende por su particular modo de ser, con su propia identidad. Y luego agrega que parecería redundante recordar la necesidad de poseer el conocimiento histórico en los niveles referidos. No obstante, indica: "Más no está demás expresar que los pueblos que no tienen memoria, están condenados a repetir los mismos errores y que la historia es "Magistra Vitae", les guste o no a los activistas y a los ideólogos que prefieren pueblos desmemoriados, o mejor, sin memoria para implantar más fácilmente sus visiones del individuo, la sociedad y el mundo."

Por su parte Luis Villorio, científico social mexicano, muy adentrado en los estudios sobre identidad en los colectivos, desde los grupos étnicos hasta las naciones, asevera: "Ninguna actividad intelectual ha logrado mejor que la historia, dar conciencia de la propia identidad a una comunidad. La historia nacional, regional o de grupos, cumplen, aun sin proponérselo, con una doble función social; por un lado favorece la cohesión al interior del grupo, por el otro refuerza actitudes de defensa y de lucha frente a los grupos externos" (citado por Muñoz 2006). Es evidente que entre todas las actividades y disciplinas del saber y del conocer, es la historia la que desempeña un rol superior en el forjamiento de la identidad. Pero es necesario diferenciar entre una actividad empírica historizante, narrativa de lo apariencial y que satisface curiosidades y provoca entretenimientos, de otra actividad que es científica, de indagación contextual, con alto grado de abstracción y profundidad en el pensamiento, lo que es la historia propiamente dicha. La historia como una disciplina científica tiene claramente definidos sus propósitos: forjar la identidad, preservar el interés social, contribuir a proyectar un mundo mejor. Igualmente, cumple la doble función social arriba asignada.

Guardando correspondencia con lo anterior, nuestro connacional José Tamayo Herrera, en su obra
Regionalización e identidad nacional (1988), reivindica el rol de la historia regional cuando expresa: "la historia regional en países como el nuestro, sumidos en el colonialismo interno y en la construcción de una identidad nacional, rescata una doble dimensión, salva la memoria colectiva de las regiones olvidadas, pero al mismo tiempo cumple una misión futurista, porque potencia en las sociedades marginadas la identidad regional!". Pero Tamayo Herrera avanza aún más al sostener que la historia regional es un formidable instrumento científico y político, con el cual el intelectual y el historiador señalan el camino y abren la trocha.

En síntesis, la historia memoria social de nuestros pueblos, pero también disciplina científica, sirve para forjar la identidad en todas sus modalidades, desde las individuales y locales, hasta las colectivas nacionales y supranacionales. La identidad es sentimiento y es autoconcepto que somos y que vamos siendo sujetos significativos a partir de la interacción con los otros significativos y con el contexto, lo que implica el conocimiento de nuestro origen y pertenencia. Asimismo, la historia sirve para compartir nuestras tradiciones, creencias, símbolos, valores, modos de comportamiento y ocupación de áreas espaciales.

Desde la particular ubicación témporoespacial y geopolítica de Tacna y del extremo sur peruano, se constata el valor de la historia para el fortalecimiento de la identidad nacional y su proyección al forjamiento de la identidad latinoamericana.

\section{LA HISTORIA ESTIMULA LA OBJETIVIDAD EN LA PERCEPCIÓN Y ACCIÓN.}

El conocimiento histórico científicamente elaborado, al ser asimilado por el sujeto, se convierte en un presupuesto teórico cn la concicncia, el cual, cn alguna situación concreta, habrá de contribuir a la acción del sujeto sobre los objetos en términos de objetividad; más aún contribuirá a la modificación o transformación de la realidad en función de algo cualitativamente diferente, pero realizable. Nuestro connacional Manuel Burga, en su interesantc obra La historia y los historiadores en el Perú (2005), nos dice que a finales del siglo XX "nuestra historiografía ha ganado mucho cn objetividad", csto por la aplicación de nuevos métodos y técnicas, de tal manera que ahora se cuenta con una mayor explicación y mejor comprensión de los procesos históricos y de la situación actual. Ante la interrogante "¿qué nos enseña la objetividad histórica?", Burga canaliza la respuesta hacia el proceso peruano indicando que la objetividad 


\section{La Vida y la Fistoria}

Panty, O. Valoración de la Función Educativa de la Historia

histórica nos permite reconocer las terribles consecuencias de la conquista; la inutilidad del sistema colonial para las sociedades ocupadas; las limitaciones de los beneficios de la cultura occidental porque llegaron en condiciones coloniales; la ineficacia del sistema republicano del siglo XIX y el nacimiento en los años 20 del siglo pasado de la nación moderna que se preocupa de las mayorías y se plantea los problemas de la ciudadanía, la modernización, las libertades, la igualdad social y la fraternidad. Refiere que entre 1532 y 1920 hubo una sucesión de esquemas políticos y económicos irracionales, en función de pequeñas élites y de metrópolis extranjeras. Finalmente en los últimos tiempos, nuevas fuerzas políticas y sociales pugnan por una ciudadanía plena.

En suma, la historia debe estudiarse evitando los prejuicios, las afectividades, las pasiones, los intereses partidistas y las ideologías. La historia se debe aprender no para reproducir lo injusto y lo degradante, sino lo que contribuya al mejoramiento de la condición humana.

\section{LA HISTORIA AYUDA A FORTALECER LA EDUCACIÓN CIUDADANA}

En las sociedades emergentes la condición ciudadana es uno de los problemas fundamentales que se advierte con la existencia de ciudadanías diferenciadas, restringidas, inconclusas y excluidas. Ser ciudadano en el buen sentido del término es disfrutar de los derechos reconocidos legalmente y aspirar al reconocimiento de otros; es ser incluido en el sistema político y el derecho a participar en la definición del sistema; es ser partícipe de la construcción colectiva de la ciudadanía y la democracia en la sociedad civil; es establecer relaciones con el Estado y al interior de la sociedad civil, es reconocer las cuestiones de género, salud, medio ambiente, multiculturalidad e interculturalidad, y es participar en el tratamiento de las mismas.

En las nuevas propuestas educativas de los Estados nacionales, los temas transversales de las respectivas programaciones curriculares son: ciudadanía e identidad. El conocimiento histórico, científicamente elaborado, puede y debe servir en el fortalecimiento de la educación ciudadana, y también de la identidad. Nuestro connacional Jorge Basadre, en sus trabajos tempranos sobre teoría de la historia, llegó a afirmar que "la historiografía interesa a todos los ciudadanos y futuros ciudadanos sin excepción y no sólo a la gente del oficio", para que puedan disponer de "una visión más profunda y más rica del presente" y puedan asumir sus compromisos con los destinos del país, según agregaba. (Basadre 1965)

Otro juicio que abona a favor de la relación Historia-educación ciudadana es el que emite el educador español Joaquín Prats, en la obra Enseñar Historia (2001), cuando expresa: " $\ldots$.. la historia tiene, por si misma, un alto poder formativo para los futuros ciudadanos, en cuanto no les enseña cuáles son las causas de los problemas actuales, pero sí sus antecedentes". Agrega, además, que la historia al analizar "problemas de las sociedades de otros tiempos, ayuda a comprender la complejidad de cualquier acontecimiento" y de "cualquier proceso".

Una educación para la ciudadanía en democracia implica por una parte, enseñar a tomar decisiones, a pensar y argumentar; por otra parte, desarrollar un aprendizaje cargado de historia y de utopía, que contribuya a poner en tensión la tradición atada al pasado y la modernidad jalonada por la imaginación del porvenir.

Concluyendo, La historia, como disciplina científica, contribuye a determinar la ubicación del ciudadano en la estructura de la sociedad, esclarece sus condiciones existenciales y promueve una actitud de superación y de mejora continua.

\section{REFERENCIAS BIBLIOGRÁFICAS}

BASADRE, Jorge. 1965. En torno a la teoría de la historia, en Historia y Cultura. Órgano del Museo Nacional de cultura. Vol.1, $N^{\circ} 1$. Lima.

BURGA, Manuel. 2005. La historia y los historiadores en el Perú. Fondo editorial de la Universidad Nacional Mayor de San Marcos. Lima.

CRICHTON, Michael. 2000. Rescate en el tiempo. Plaza \& Jame. Barcelona.

CROCE Benedetto. 1948. La historia como hazaña de la libertad. Fondo de Cultura Económica. México.

MUNOZ SERRANO R. 2006. Historia crítica y educación holística.

http://www.observatorio.org/colaboraciones/serrano.html GARCÍA GODOY, Cristian. 2006. Globalización, identidad nacional c idioma.

http://gacetaiberoamericana.com/issues/volXINr3kitz.html TAMAYO HERRERA, José. 1988. Regionalización e identidad nacional. CEPAR. Lima. 